\title{
Societal cost-effectiveness analysis of the 21-gene assay in estrogen-receptor-positive, lymph-node-negative early-stage breast cancer in Japan
}

Hideko Yamauchi', Chizuko Nakagawa', Shinji Yamashige ${ }^{2}$, Hiroyuki Takei $^{3}$, Hiroshi Yagata', Atsushi Yoshida', Naoki Hayashi', John Hornberger ${ }^{4,5^{*}}$, Tiffany Yu ${ }^{4}$, Calvin Chao ${ }^{6}$, Carl Yoshizawa ${ }^{6}$ and Seigo Nakamura ${ }^{1,7}$

\begin{abstract}
Background: Breast-cancer incidence and mortality have been increasing in Japan. Japanese-specific clinical validity and utility data for the 21-gene assay (Oncotype DX ${ }^{\circledR}$ Breast Cancer Assay; Genomic Health, Inc., Redwood City, USA) are now available. The objective of this study was to evaluate the cost-effectiveness of the 21-gene assay for the guidance of adjuvant chemotherapy decisions in estrogen-receptor-positive, lymph-node-negative, early-stage breast cancer patients, from the Japanese societal perspective.

Methods: The recurrence risk group distribution by the 21-gene assay result and the assay's influence on adjuvant chemotherapy recommendations were obtained from a study of 104 patients. A state-transition cohort (Markov) model tracked time from surgery until distant recurrence and from distant recurrence to death. Adjuvant chemotherapy benefit by 21-gene assay risk group was based on published clinical validation studies. Direct and indirect medical costs were obtained from the referral centers. Utilities associated with progression and chemotherapy-related adverse events were extracted from literature. Sensitivity analyses assessed the key drivers and robustness of the primary outcomes.

Results: The 21 -gene assay identified $48 \%$ of patients as low-risk, $36 \%$ as intermediate-risk, and $16 \%$ as high-risk. Total acute chemotherapy-related costs decreased by $¥ 154,066$ due to less adjuvant chemotherapy usage. In the high-risk group, adjuvant chemotherapy use increased 18\%, leading to survival benefits. Chemotherapy use overall decreased by $19 \%$. Monitoring costs increased by $¥ 3,744$ but recurrence costs declined by $¥ 46,113$ per patient. Use of the 21-gene assay increased quality-adjusted-life-years (QALYS) by 0.241 per patient on average; the net cost per QALY gained was $¥ 636,752(\$ 6,368)$.
\end{abstract}

Conclusions: The 21-gene assay for women with estrogen-receptor-positive, lymph-node-negative, early-stage breast cancer is projected to be cost-effective in Japan.

Keywords: Breast cancer, Cost-effectiveness, Cost-benefit, Molecular diagnostic testing, Genetic testing

\footnotetext{
* Correspondence: ujch@stanford.edu

${ }^{4}$ Cedar Associates LLC, Menlo Park, CA, USA

${ }^{5}$ School of Medicine, Stanford University, Stanford, CA, USA

Full list of author information is available at the end of the article
} 


\section{Background}

Breast cancer is the most common cancer among Japanese women, with approximately 40,000 women diagnosed every year [1-3]. Although the breast-cancer-specific mortality rate is declining in the United States and other Western countries, it is rising in Japan [4]. At diagnosis, at least $83 \%$ of breast cancer in Japan present with earlystage disease (stages 0, I, II, or IIIa) [5,6]; more than $60 \%$ have no lymph node involvement (LN-), and $74 \%$ have estrogen-receptor-positive $(\mathrm{ER}+)$ breast cancer.

Guidelines issued by the National Comprehensive Cancer Network (NCCN) and the expert panel at the 2011 St. Gallen International Breast Cancer Conference indicate that patients with ER+, LN- early-stage breast cancer (ESBC) have the options of systemic adjuvant treatment with either endocrine therapy and/or chemotherapy $[7,8]$. They recommend that clinicians consider selecting candidates for adjuvant chemotherapy to prevent distant recurrence on the basis of clinical and pathologic features, such as patient age, tumor size, degree of lymph node involvement, and tumor differentiation. The potential risk reduction in distant recurrence must be weighed against the risks of adverse events with adjuvant chemotherapy; at least $10 \%$ of patients experience serious or life-threatening adverse effects with chemotherapy treatment [9].

The 21-gene assay (Oncotype DX ${ }^{\oplus}$ Breast Cancer Assay; Genomic Health, Inc., Redwood City, USA) has been shown to predict local and distant recurrence risk, survival, and chemotherapy benefit in ER+ ESBC [10-16]. The 21-gene assay has been commercially available in Japan since 2007. Two observational studies published in 2010 support the validation of the assay in Japan as a strong predictor of distant recurrence risk $[3,17]$. Toi et al. conducted a prospective analysis of previously archived tumor samples from 200 women who had ER+, LN- ESBC and had undergone tamoxifen treatment at eight highvolume centers throughout Japan [17]. The distant recurrence rate at 10 years among Japanese women with ER+, LN- ESBC was $9.6 \%$ on average, but as high as $24.8 \%$ in the high-risk group. Yorozuya et al. conducted a retrospective, case-control study in 40 patients who had surgery for ER+, LN- ESBC in Japan [3]. They found that the 21-gene assay had stronger predictive power than tumor histological grade.

A study at tertiary referral centers in Tokyo and Saitama, Japan evaluated 104 women with ER+ ESBC, either without nodal involvement or with micrometastases, and showed that the 21 -gene assay changed $33 \%$ of the adjuvant chemotherapy treatment recommendations, resulting in a net $19 \%$ absolute reduction in chemotherapy use [18]. Using the decision impact data from Japanese clinical practice, this study aimed to evaluate the cost-effectiveness of the 21-gene assay compared to traditional prognostic indicators for the guidance of adjuvant chemotherapy decisions in ER+, LN- ESBC patients from a societal perspective in Japan.

\section{Methods}

This analysis considered Japanese women with ER+, LN(including micrometastases) ESBC who were eligible for treatment with adjuvant chemotherapy after having undergone surgery for primary tumor removal and lymph node dissection.

\section{Analytical framework}

Outcomes and costs were assessed from a Japanese societal perspective from surgery to death using a state-transition cohort (Markov) model (Figure 1). The primary comparator was clinical practice where risk assessment for 10-year distant recurrence was based on traditional clinicopathological factors recommended in guidelines [7]. The intervention was use of the 21-gene assay (Oncotype DX ${ }^{\odot}$ Breast Cancer Assay; Genomic Health, Inc., Redwood City, USA) to stratify patients into 3 risk groups - low, intermediate, or high. The probabilities of recommendations in favor of adjuvant chemotherapy before and after availability of the patients' 21-gene assay results were obtained from the tertiary referral center study [18]. Thereafter, the model followed the incidence of distant recurrence, breastcancer-related mortality, and non-breast-cancer-related mortality.

Direct medical costs were included for the 21-gene assay, adjuvant chemotherapy, surveillance (2 outpatient visits per year), adverse events and distant recurrence. Indirect costs included travel expenses, and patient time for travel and treatment. All costs are reported in 2013 Japanese Yen (JPY, ¥). Cost data from previous years were adjusted using consumer price indices for medical services and public transportation published by the Statistics Bureau of Japan [19], and wage indices published by the Japanese Ministry of Health, Labour and Welfare [20]. Summaries are provided selectively in United States Dollars (USD, \$; conversion rate: $100 \mathrm{JPY}=1 \mathrm{USD}$ ) for comparison.

Costs and benefits of treatment were discounted at a 3\% annual rate, which is in accordance with recommendations from the International Society for Pharmacoeconomics and Outcomes Research (ISPOR) [21] and has been used in prior cost-effectiveness studies in Japan $[22,23]$. Inputs were varied individually in a one-way sensitivity analysis to evaluate the effects of each input variable's uncertainty on the assay's incremental costeffectiveness ratio (cost per QALY gained).

\section{Data sources and assumptions}

Impact of the 21-gene assay score on recommendations to use adjuvant chemotherapy

The tertiary referral centers study found that recommendations for adjuvant chemotherapy decreased by 


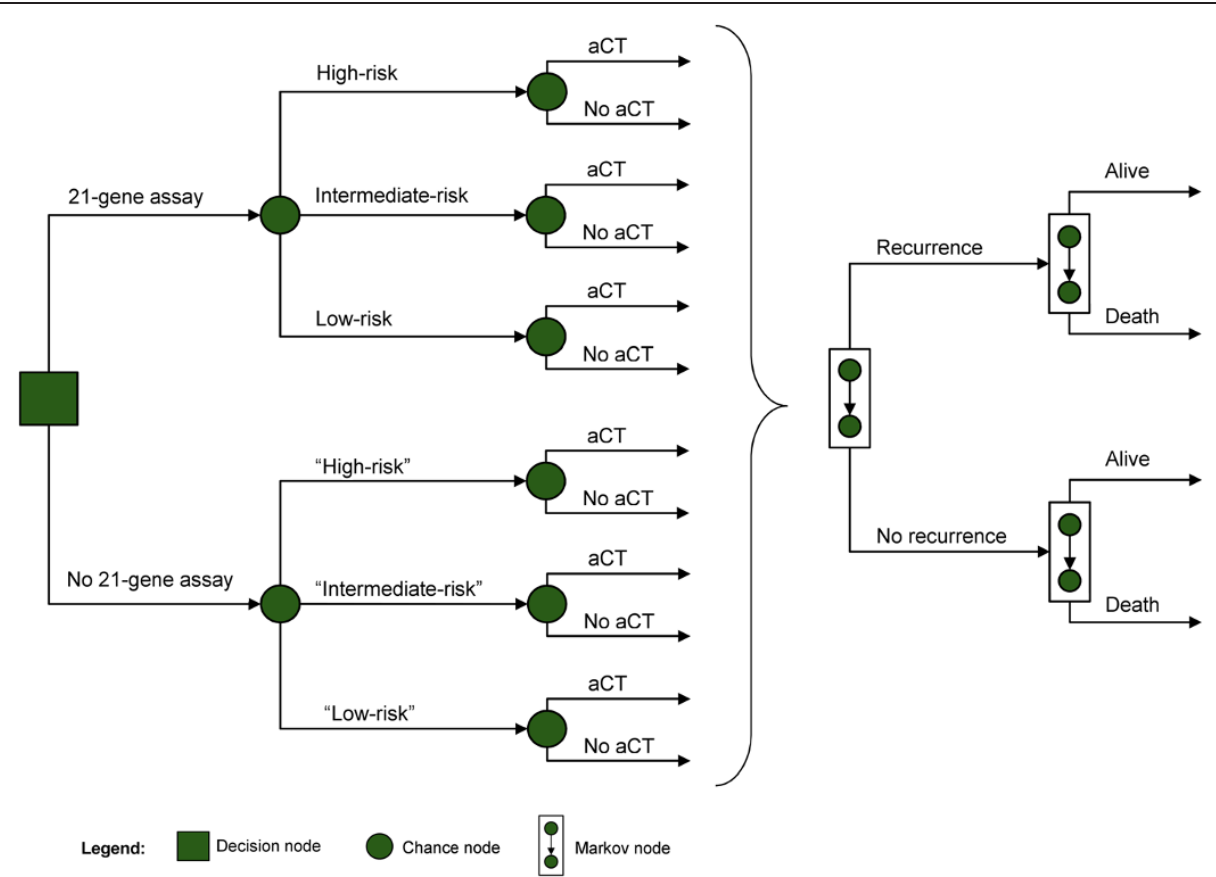

Figure 1 Markov diagram. The level of recurrence risk is based on the 21-gene assay. Quotation marks indicate values unknown to physicians and patients. Abbreviation: aCT, adjuvant chemotherapy.

$19 \%$ overall as a result of using the 21 -gene assay (Table 1) [18]. None of the women identified as having low distant recurrence risk were recommended to adjuvant chemotherapy after receiving their 21 -gene assay results, down from $32 \%$ prior to testing. In the intermediate risk group, $19 \%$ fewer were recommended adjuvant chemotherapy, whereas recommendations increased by $18 \%$ in the high risk group.

\section{Probability of recurrence, mortality, and adjuvant chemotherapy adverse events}

Estimates of the baseline recurrence risk in Japan by the 21-gene assay's risk groups were extracted from Toi et al., who studied the clinical validity of the assay in a Japanese population of 200 women with LN- ESBC (Table 2) [17]. These rates were lower than those

Table 1 Influence of the 21-gene assay on adjuvant chemotherapy recommendations

\begin{tabular}{lccc}
\hline $\begin{array}{l}\text { Patient } \\
\text { population* }\end{array}$ & \multicolumn{3}{c}{$\begin{array}{c}\text { Patients recommended by physicians to adjuvant } \\
\text { chemotherapy, n (\%) }\end{array}$} \\
\cline { 2 - 4 } & Prior to assay & After assay & Change \\
\hline All & $48(46.2)$ & $28(26.9)$ & $-20(-19.2)$ \\
Low-risk & $16(32.0)$ & $0(0.0)$ & $-16(-32.0)$ \\
Intermediate-risk & $18(48.6)$ & $11(29.7)$ & $-7(-18.9)$ \\
High-risk & $14(82.4)$ & $17(100.0)$ & $3(17.6)$ \\
\hline
\end{tabular}

*Risk group determined by the 21-gene assay. Risk groups: zero to 17 is low-risk, 18 to 30 is intermediate-risk, greater than 30 is high-risk. Source: Yamauchi et al. Clin Breast Cancer 2013 [18]. previously reported for women from the US and UK $[11,14]$. Data on the benefit of chemotherapy by 21 -gene assay risk group were extracted from a separate validation study of patients from NSABP B-20 [15].

Japanese-specific risks of grade 1, 2, or 3 adverse events were extracted from unpublished data from St. Luke's Hospital analyzed by Tsugawa et al. The risk of fatal toxicity from adjuvant chemotherapy was extracted from Hillner and Smith [24]. The annual risk of dying from non-breast-cancer-related causes was based on population mortality rate data in Japan [25]. The annual risk of dying from breast-cancer-related causes after recurrence was extracted from previous models [22,23].

\section{Costs}

The price of the 21-gene assay was set equal to the list price in Japan, $(¥ 350,000)$. The cost of chemotherapy, $¥ 561,813$, was based on data from one of the tertiary referral centers, St. Luke's Hospital in Tokyo, Japan (Table 2). The total direct medical costs of salvage treatment and palliative care from the time of distant recurrence to time of death in Japan is $¥ 4,710,584$ [22], representing an annual cost after recurrence equal to $¥ 2,405,924$. Costs to patients and payers to manage adverse events were obtained from the tertiary referral center study and weighted by the proportion of patients who experienced the event. Additional indirect patient time and transportation costs were derived as the sum of lost time (valued based on average hourly wage in 
Table 2 Model inputs

\begin{tabular}{|c|c|c|c|c|}
\hline \multirow[t]{2}{*}{ Parameter } & \multirow[t]{2}{*}{ Mean } & \multicolumn{2}{|c|}{ Sensitivity analysis } & \multirow[t]{2}{*}{ Source } \\
\hline & & Low & High & \\
\hline \multicolumn{5}{|c|}{ Baseline recurrence risk by 21-gene assay risk group } \\
\hline \multicolumn{5}{|l|}{ Japan } \\
\hline Low-risk & $3.3 \%$ & $1.1 \%$ & $10.0 \%$ & [17] \\
\hline Intermediate-risk & $0.0 \%$ & $0.0 \%$ & $0.0 \%$ & [17] \\
\hline High-risk & $24.8 \%$ & $15.7 \%$ & $37.8 \%$ & {$[17]$} \\
\hline \multicolumn{5}{|l|}{ US and UK } \\
\hline Low-risk & $5.4 \%$ & $3.6 \%$ & $8.5 \%$ & {$[11,14]$} \\
\hline Intermediate-risk & $13.7 \%$ & $8.6 \%$ & $20.0 \%$ & {$[11,14]$} \\
\hline High-risk & $29.2 \%$ & $21.6 \%$ & $37.2 \%$ & {$[11,14]$} \\
\hline \multicolumn{5}{|c|}{ Relative reduction of recurrence with aCT by 21-gene assay risk group } \\
\hline Low-risk & $0 \%$ & $0 \%$ & $54 \%$ & [15] \\
\hline Intermediate-risk & $39 \%$ & $0 \%$ & $76 \%$ & [15] \\
\hline High-risk & $74 \%$ & $47 \%$ & $87 \%$ & [15] \\
\hline \multicolumn{5}{|l|}{ Costs* } \\
\hline 21-gene assay & $¥ 350,000(\$ 3,500)$ & $¥ 262,500$ & $¥ 437,500$ & List price \\
\hline \multicolumn{5}{|l|}{ Associated with aCT } \\
\hline Drugs & $¥ 561,813(\$ 5,618)$ & $¥ 280,907$ & $¥ 1,500,000$ & St. Luke's Hospital (Tokyo, Japan) \\
\hline Adverse events & $¥ 170,831(\$ 1,708)$ & $¥ 85,416$ & $¥ 256,247$ & St. Luke's Hospital (Tokyo, Japan), [24] \\
\hline Patient time and transportation & $¥ 68,500(\$ 685)$ & $¥ 34,250$ & $¥ 102,750$ & St. Luke's Hospital (Tokyo, Japan) \\
\hline Surveillance (2 visits/year) & $¥ 25,416(\$ 254)$ & $¥ 12,708$ & $¥ 38,124$ & [23] \\
\hline Per recurrence per year & $¥ 2,405,924(\$ 24,059)$ & $¥ 1,202,962$ & $¥ 3,608,886$ & [22] \\
\hline \multicolumn{5}{|l|}{ Quality of life } \\
\hline No recurrence, no aCT & 0.98 & 0.78 & 1.00 & [23] \\
\hline Progression & 0.30 & 0.24 & 0.36 & {$[26,27]$} \\
\hline QALY tariff of aCT & 0.53 & 0.43 & 0.64 & {$[23,24,28]$} \\
\hline \multicolumn{5}{|l|}{ Other assumptions } \\
\hline Age & 49.8 & 35 & 75 & St. Luke's Hospital (Tokyo, Japan) \\
\hline Annual mortality risk after progression & $40 \%$ & $20 \%$ & $60 \%$ & {$[22,23]$} \\
\hline Time horizon, years & Lifetime & & & ISPOR guidelines \\
\hline
\end{tabular}

Abbreviations: $¥$, JPY Japanese Yen, \$, USD United States Dollar, aCT adjuvant chemotherapy, QALY quality-adjusted-life-year, ISPOR International Society For Pharmacoeconomics and Outcomes Research.

A 3\% time preference discount rate was applied in the basecase scenario (lower bound, 1\%; upper bound, 5\%) [21].

*Per patient on average. Reported in 2013 currency. Conversion rate is 100 JPY per 1 USD.

Japan) and transportation expenses (train fares) for visits related to adjuvant chemotherapy.

\section{Quality of life}

Health utility scores and quality-adjusted-life-year (QALY) tariffs were used to calculate QALYs. Health utility scores range from 0 for death to 1 for perfect health and quantify the desirability of a particular health state. QALY tariffs represent the reduction in QALYs caused by a procedure or event. These measures of patient preference and quality-of-life were extracted from published cost-effectiveness analyses in Japan and time-trade-off patient surveys (Table 2) [23,26-28]. QALYs were computed as the lifetime sum of the product of each health state utility and mean time in that health state (adjusted for fixed annual discount rate).

\section{Data analysis}

The changes in QALYs related to the immediate disutility of adjuvant chemotherapy and the later disutility of recurrence were analyzed. The lifetime costs and costeffectiveness of the 21-gene assay versus current clinical practice were also reported. The main analysis employed estimates of distant recurrence risk from a Japanese 
validation study [17]. An alternative scenario was also evaluated with estimates of distant recurrence risk from US- and UK-based clinical validation studies $[11,14]$.

One-way sensitivity analyses were conducted to assess the robustness of the primary endpoint (cost per QALY gained). Each parameter was varied across its individual range to evaluate the effect of the parameters' uncertainty on the results. The range for each parameter was extracted from $95 \%$ confidence intervals if reported, and broad ranges $( \pm 25 \%$ to $\pm 50 \%)$ otherwise.

\section{Results}

Reduction in adjuvant chemotherapy use (19\%) due to the 21-gene assay led to immediate gains of 0.103 QALYs per patient (Table 3). The 21-gene assay increased adjuvant chemotherapy use and reduced distant recurrence risk among high-risk patients, resulting in an additional average later-term gain of 0.139 QALYs per patient, assuming baseline risk estimates from the Japanese validation study (Table 3a). In total, the 21-gene assay led to an average increase of 0.241 QALYs per patient.

The 21-gene assay cost $¥ 350,000$. Reductions in costs associated with adjuvant chemotherapy (-¥108,041), adverse events $(-¥ 32,852)$, patient time and transportation (-¥13,173), and distant recurrence $(-¥ 46,113)$ offset the testing cost. Delay and/or prevention of recurrence increased monitoring costs by $¥ 3,744$. Total lifetime costs increased $¥ 153,565$ per patient with the 21 -gene assay, resulting in an incremental cost-effectiveness ratio of $¥ 636,752(\$ 6,368)$ per QALY gained.

In the alternative analysis, assuming the higher US and UK baseline distant recurrence risk estimates, the 21gene assay increased QALYs by 0.160 years per patient on average (Table $3 \mathrm{~b}$ ). The QALY increase related to recurrence-free-survival improvement was smaller in this scenario (0.057) due to the greater likelihood of recurrence.

Lifetime costs in this alternative scenario increased by $¥ 180,369$ per patient on average with the 21 -gene assay. Monitoring costs increased by $¥ 1,537$, while the costs to manage distant recurrence decreased by $¥ 17,102$. Other costs were identical to the main analysis. The higher US and UK recurrence risks lead to less recurrence-related savings and a smaller increase in monitoring costs, resulting in a greater increase in lifetime costs compared to the main analysis. The cost per QALY gained in the alternative scenario was $¥ 1,129,442$ ( $\$ 11,294)$.

With Japanese distant recurrence risk data, the parameters whose change or uncertainty most altered the cost per QALY gained in the one-way sensitivity analysis were the: (1) cost of chemotherapy drugs, (2) cost of the 21gene assay, and (3) patient's age at diagnosis (Figure 2). The maximum cost per QALY gained was $¥ 1,189,962$ $(\$ 11,900)$, which resulted only if the average age of diagnosis rose from 49.8 to 75 . The next highest cost per QALY gained, $¥ 1,177,069$ (\$11,771), resulted only if the relative distant recurrence risk reduction due to chemotherapy in low-risk patients (the fourth most influential variable) was increased from the base-case value of zero to $54 \%$. These were the only two scenarios under which the projected cost per QALY gained was above $¥ 1,000,000$.

Given US- and UK-based distant recurrence risk data, the parameters whose change or uncertainty most altered the cost per QALY gained were the: (1) relative distant recurrence risk reduction due to chemotherapy in low-risk patients and (2) in intermediate-risk patients, and (3) cost of chemotherapy drugs (Figure 3). Once again, increasing the relative distant recurrence risk reduction due to chemotherapy in low-risk patients from zero to $54 \%$ results in the highest cost per QALY gained. This scenario's cost per QALY gained was unusually high at $¥ 10,142,498 \quad(\$ 101,425)$; the next highest cost per QALY gained was $¥ 3,703,793$ ( $\$ 37,038)$, which resulted when the relative distant recurrence risk reduction due to chemotherapy in intermediate risk patients was increased from $39 \%$ to $76 \%$.

Cost-savings were predicted with the 21-gene assay when adjuvant chemotherapy drug costs increased beyond $¥ 1,360,351 \quad(\$ 13,604)$ given Japanese distant recurrence risk data. With US- and UK-based distant recurrence data, cost-savings were predicted when adjuvant chemotherapy drug costs exceeded $¥ 1,499,733$ (\$14,997). These values were comparable to the drug costs of some regimens containing prophylactic granulocyte colony-stimulating factor (G-CSF) reported by Ishiguro et al. in 2010 [22].

\section{Discussion}

Using actual chemotherapy recommendations in a Japanese setting, this study found that the use of the 21-gene assay resulted in an increase of 0.241 QALYs and increased lifetime costs of $¥ 153,565$ per patient on average. The consequent cost per QALY gained was $¥ 636,752$ (\$6,368).

Previously, 21-gene assay recommendations were compared with St. Gallen guideline criteria in a societal costeffectiveness analysis by Kondo et al. [23]. Guidelines have been used as surrogate decision impact parameters in cost-effectiveness studies of diagnostics early in their development or diffusion when use is fairly limited [29]. As clinical decision impact data becomes available, it is important to validate those analyses that used surrogate parameters, as has been done for the 21-gene assay in other settings $[30,31]$. The study herein built upon previous work to provide the first available societal costeffectiveness estimate in Japan, applying actual recommendations for chemotherapy from a tertiary referral center. This study included direct chemotherapy- and distant recurrence-related costs, and indirect costs associated with time dedicated to treatment and transportation fees. 
Table 3 Base-case results

\begin{tabular}{|c|c|c|c|}
\hline \multicolumn{4}{|c|}{ A. Baseline recurrence risk from a Japan-based validation study } \\
\hline Main analysis & Without 21-gene assay & With 21-gene assay & Difference \\
\hline Proportion receiving adjuvant chemotherapy & $46.2 \%$ & $26.9 \%$ & $-19.2 \%$ \\
\hline 10-year recurrence-free survival, \% & $94.5 \%$ & $95.0 \%$ & $0.5 \%$ \\
\hline \multicolumn{4}{|l|}{ QALYS } \\
\hline Adjuvant chemotherapy (immediate) & -0.246 & -0.144 & 0.103 \\
\hline Recurrence (long-term) & 21.093 & 21.231 & 0.139 \\
\hline Total & 20.847 & 21.088 & 0.241 \\
\hline \multicolumn{4}{|l|}{ Costs* $^{*}$} \\
\hline 21-gene assay & & $¥ 350,000$ & $¥ 350,000$ \\
\hline \multicolumn{4}{|l|}{ Acute costs } \\
\hline Chemotherapy drugs & $¥ 259,298$ & $¥ 151,257$ & $-¥ 108,041$ \\
\hline Adverse events & $¥ 78,845$ & $¥ 45,993$ & $-¥ 32,852$ \\
\hline Patient time and transportation & $¥ 31,615$ & $¥ 18,442$ & $-¥ 13,173$ \\
\hline Monitoring costs until recurrence & $¥ 520,493$ & $¥ 524,238$ & $¥ 3,744$ \\
\hline \multirow[t]{4}{*}{ Costs after recurrence } & $¥ 347,446$ & $¥ 301,333$ & $-¥ 46,113$ \\
\hline & $¥ 1,237,698$ & $¥ 1,391,263$ & $¥ 153,565$ \\
\hline & Cost per QALY gained & JPY & $¥ 636,752$ \\
\hline & & USD & $\$ 6,368$ \\
\hline \multicolumn{4}{|c|}{ B. Baseline recurrence risk from US- and UK-based validation studies } \\
\hline Alternative analysis & Without 21-gene assay & With 21-gene assay & Difference \\
\hline Proportion receiving adjuvant chemotherapy & $46.2 \%$ & $26.9 \%$ & $-19.2 \%$ \\
\hline 10-year recurrence-free survival, \% & $89.4 \%$ & $89.6 \%$ & $0.3 \%$ \\
\hline \multicolumn{4}{|l|}{ QALYS } \\
\hline Adjuvant chemotherapy (immediate) & -0.246 & -0.144 & 0.103 \\
\hline Recurrence (long-term) & 19.533 & 19.590 & 0.057 \\
\hline Total & 19.287 & 19.447 & 0.160 \\
\hline \multicolumn{4}{|l|}{ Costs $^{*}$} \\
\hline 21-gene assay & & $¥ 350,000$ & $¥ 350,000$ \\
\hline \multicolumn{4}{|l|}{ Acute costs } \\
\hline Chemotherapy drugs & $¥ 259,298$ & $¥ 151,257$ & $-¥ 108,041$ \\
\hline Adverse events & $¥ 78,845$ & $¥ 45,993$ & $-¥ 32,852$ \\
\hline Patient time and transportation & $¥ 31,615$ & $¥ 18,442$ & $-¥ 13,173$ \\
\hline Monitoring costs until recurrence & $¥ 478,260$ & $¥ 479,798$ & $¥ 1,537$ \\
\hline \multirow[t]{4}{*}{ Costs after recurrence } & $¥ 899,695$ & $¥ 882,593$ & $-¥ 17,102$ \\
\hline & $¥ 1,747,715$ & $¥ 1,928,084$ & $¥ 180,369$ \\
\hline & Cost per QALY gained & JPY & $¥ 1,129,442$ \\
\hline & & USD & $\$ 11,294$ \\
\hline
\end{tabular}

Abbreviations: QALY quality-adjusted-life-year, ¥, JPY Japanese Yen, \$, USD United States Dollar. *Per patient on average. Reported in 2013 currency.

The one-way sensitivity analysis showed that the cost per QALY gained was less than $¥ 1,189,962 \quad(\$ 11,900)$ across all ranges of parameters. The cost-effectiveness ratio was highest when patient age at diagnosis was high or chemotherapy was assumed to be extremely beneficial for low-risk patients. The $95 \%$ confidence interval for the effect of chemotherapy in low-risk patients was very wide, and $84 \%$ of that range indicated no benefit to chemotherapy for low-risk patients [15].

The largest change in the cost per QALY gained in the one-way sensitivity analysis resulted when the cost of chemotherapy drugs was varied. This finding is especially 


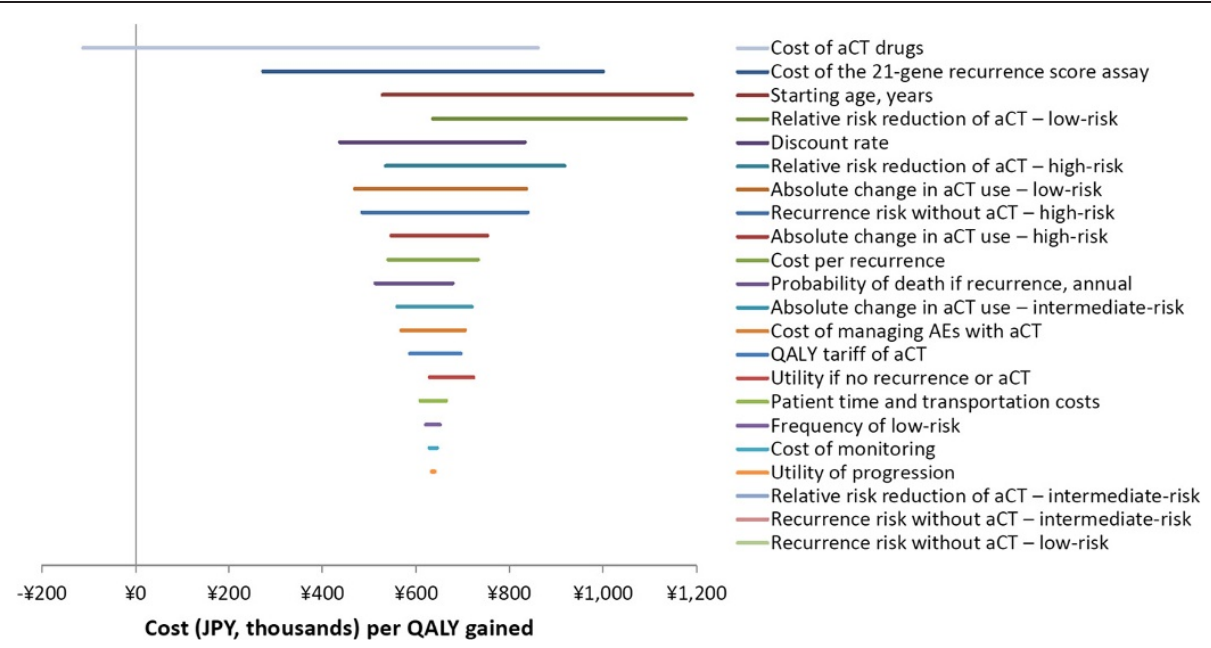

Figure 2 One-way sensitivity analysis tornado diagram: baseline recurrence risk from a Japan-based validation study. Abbreviations: aCT, adjuvant chemotherapy; AEs, adverse events; QALY, quality-adjusted-life-year; $¥$, JPY, Japanese Yen in 2013 currency.

relevant as third-generation regimens using G-CSF have recently been reported to have a cost-effectiveness ratio lower than the commonly accepted threshold value (¥6 million per QALY gained) [22]. If adjuvant chemotherapy drug costs increase to the values previously reported for G-CSF-containing chemotherapy regimens in Japan, this model shows that the 21 -gene assay would be cost-saving, regardless of the distant recurrence risk data source.

The 21-gene assay validation study in Japan showed no distant recurrences in the intermediate-risk group [17]. Therefore, the benefit of chemotherapy for the intermediate group had no effect on the cost or QALY results in the main analysis. By contrast, US- and UK-based validation studies showed higher distant recurrence risks overall, increasing from the low- to intermediate- to high-risk groups. When estimates from the US- and UK-based studies were applied, varying the benefit (relative risk reduction) due to chemotherapy in the intermediate-risk group in the one-way sensitivity analysis led to the second-largest change in the cost per QALY gained result.

Applying real chemotherapy recommendation changes, this analysis' findings differed from those of a previous analysis by Kondo et al. in several significant respects [23]. Total QALYs were slightly higher in this study (20.8 years without and 21.1 years with the 21-gene assay) than in Kondo et al. (19.5 years without and 20.1 years with); however, the QALYs gained in this study (0.241) was less than half of that reported by Kondo et al. (0.63). In this analysis, the lifetime costs do not exceed $¥ 2$ million in any of the scenarios tested regardless of 21-gene assay use, whereas Kondo et al. reported costs exceeding ¥3 million. Using US- and UK-based recurrence risk estimates

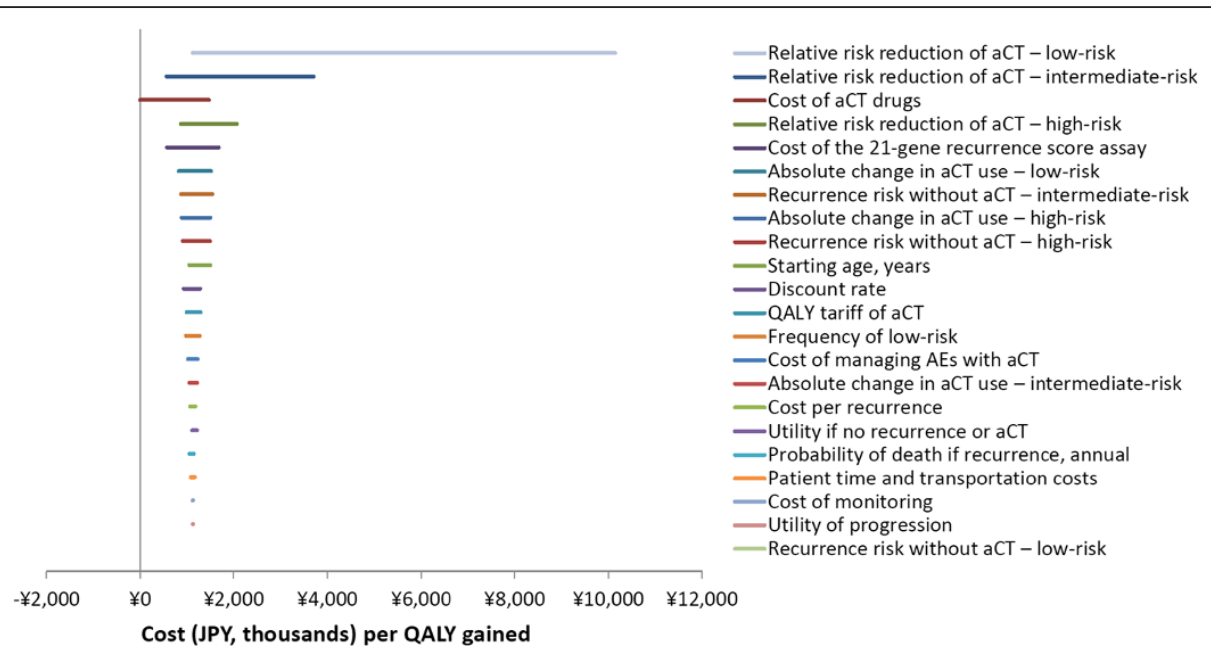

Figure 3 One-way sensitivity analysis tornado diagram: baseline recurrence risk from a US- and UK-based validation studies. Abbreviations: aCT, adjuvant chemotherapy; AEs, adverse events; QALY, quality-adjusted-life-year; ¥, JPY, Japanese Yen in 2013 currency. 
lowered the total QALYs results. In this analysis, total QALYs was 19.3 years without and 19.4 years with the 21-gene assay, slightly below those reported by Kondo et al. The 0.160 QALY gain projected here is approximately one-fourth of the gain estimated by Kondo et al. Factors that may have led to the differences include (1) a larger decrease in recommendations in favor of adjuvant chemotherapy found in actual clinical practice (19\% herein versus $8 \%$ when applying St. Gallen criteria) and (2) a target population selection that excluded patients with HER2+ tumors who would presumably receive trastuzumab regardless of the 21-gene assay result. Given the unexplained differences among these model findings, it may be a useful exercise to directly and collaboratively cross-validate the available models, as has been performed in other fields [32].

Several limitations are important to consider when interpreting the results of this study. First, the decision impact study at the tertiary center excluded women (1) whose recurrence risk was assessed by a physician as very low, (2) who had already chosen to undergo chemotherapy, or (3) who could not afford to participate. Therefore, the proportion of patients whose treatment recommendations are altered by the 21-gene assay may be different if the assay were used without consideration of these exclusion criteria. Second, utilities estimates from Japanese women are not available. For more than two decades, it has been well-established that attitudes about cancer and its treatments may differ across countries [33]. It would be relevant in the future to have information from studies on patients' experiences in Japan, especially utility data. Finally, the 21 -gene assay has recently been shown to also predict local recurrence [13]. Excluding this outcome benefit predictably underestimates the benefits to patients and cost-savings to society. This analysis likely overestimated the cost per QALY gained with the 21-gene assay compared to clinical practice using traditional clinicopathological factors.

\section{Conclusions}

Previous analyses concluded that the 21-gene assay "is indicated as cost-effective in Japan" when compared to clinical guidelines [23]. This new analysis, which incorporated clinical recommendations made in Japanese tertiary referral centers, supports this finding.

\footnotetext{
Abbreviations

ER+: Estrogen-receptor-positive; LN-: Lymph-node-negative; ESBC: Early-stage breast cancer; NCCN: National Comprehensive Cancer Network; ISPOR: International Society for Pharmacoeconomics and Outcomes Research; QALY: Quality-adjusted-life-year; JPY: Japanese Yen; USD: United States Dollar; aCT: Adjuvant chemotherapy; G-CSF: Granulocyte colony-stimulating factor.
}

\section{Competing interests}

Genomic Health, Inc. (Redwood City, CA, USA) sponsored the study. CC and $\mathrm{CY}$ are employed by the sponsor. JH and TY are employees of Cedar Associates, LLC, an independent research consulting firm retained by the sponsor. HYamauchi and SN have received honoraria from SRL, Inc. SN and CN serve as consultants for Genomic Health, Inc.

\section{Authors' contributions}

All authors contributed to the design of the analysis. HYamauchi, CN, SY, HT, HYagata, AY, NH, and SN participated in the collection and interpretation of clinical data and contributed to the clinical validation of the cost-effectiveness analysis design. JH and TY constructed the Markov analysis and drafted the manuscript. CC and CY participated in the statistical validation and interpretation. All authors read and approved the final manuscript.

\section{Authors' information}

$\mathrm{JH}$ is a member of the Ethics Committee for the American Society of Clinical Oncology, co-chair of the Health Science Task Force on Communicating Health Economics Research in the International Society for Pharmacoeconomics and Outcomes Research (ISPOR), and co-editor of the Value in Health journal published on behalf of ISPOR.

\section{Acknowledgements}

The authors would like to thank Rebecca Chien for her contributions to the structure and inputs to the decision analytic framework. This work was supported by Genomic Health, Inc. (Redwood City, CA, USA).

\section{Author details}

${ }^{1}$ Department of Breast Surgery, St. Luke's International Hospitalcph, Tokyo, Japan. ${ }^{2}$ Graduate School of Economics, Hitotsubashi University, Tokyo, Japan. ${ }^{3}$ Division of Breast Surgery, Saitama Cancer Center, Saitama, Japan. ${ }^{4}$ Cedar Associates LLC, Menlo Park, CA, USA. ${ }^{5}$ School of Medicine, Stanford University, Stanford, CA, USA. ${ }^{6}$ Genomic Health, Inc, Redwood City, CA, USA.

${ }^{7}$ Department of Breast Surgery, Showa University, Tokyo, Japan.

Received: 12 December 2013 Accepted: 29 August 2014

Published: 5 September 2014

\section{References}

1. Kamo K, Katanoda K, Matsuda T, Marugame T, Ajiki W, Sobue T: Lifetime and age-conditional probabilities of developing or dying of cancer in Japan. Jpn J Clin Oncol 2008, 38:571-576.

2. Sonoo $H$, Fukuda M: Results of questionnaires concerning breast cancer surgery in Japan 1980-2003. Breast Cancer 2005, 12:1-2.

3. Yorozuya K, Takeuchi T, Yoshida M, Mouri Y, Kousaka J, Fujii K, Nakano S, Fukutomi T, Hara K, Ichihara S, Lin Y, Kikuchi S: Evaluation of Oncotype DX Recurrence Score as a prognostic factor in Japanese women with estrogen receptor-positive, node-negative primary Stage I or IIA breast cancer. J Cancer Res Clin Oncol 2010, 136:939-944.

4. Toi M, Ohashi Y, Seow A, Moriya T, Tse G, Sasano H, Park BW, Chow LW, Laudico AV, Yip CH, Ueno E, Ishiguro H, Bando H: The Breast Cancer Working Group presentation was divided into three sections: the epidemiology, pathology and treatment of breast cancer. Jpn J Clin Oncol 2010, 40:i13-i18.

5. American Joint Commitee on Cancer: Breast Cancer Staging, 7th edition. https:// cancerstaging.org/referencestools/quickreferences/Documents/BreastLarge.pdf.

6. The Japanese Breast Cancer Society: Investigative report on registration of breast cancer patients in Japan: 2006. http://www.jbcs.gr.jp/english_new/ REPORT/REPORT.pdf

7. Gnant M, Harbeck N, Thomssen C: St. Gallen 2011: summary of the consensus discussion. Breast Care (Basel) 2011, 6:136-141.

8. National Comprehensive Cancer Network ${ }^{\oplus}$ : NCCN clinical practice guidelines in oncology ${ }^{\otimes}$ : breast cancer version 3.2014. http://www.nccn. org/professionals/physician_gls/f_guidelines.asp.

9. Hassett MJ, O'Malley AJ, Pakes JR, Newhouse JP, Earle CC: Frequency and cost of chemotherapy-related serious adverse effects in a population sample of women with breast cancer. J Natl Cancer Inst 2006, 98:1108-1117.

10. Albain KS, Barlow WE, Shak S, Hortobagyi GN, Livingston RB, Yeh IT, Ravdin $P$, Bugarini R, Baehner FL, Davidson NE, Sledge GW, Winer EP, Hudis C, Ingle JN, Perez EA, Pritchard Kl, Shepherd L, Gralow JR, Yoshizawa C, Allred DC, Osborne CK, Hayes DF: Prognostic and predictive value of the 21-gene recurrence score assay in postmenopausal women with node-positive, oestrogen-receptor-positive breast cancer on chemotherapy: a retrospective analysis of a randomised trial. Lancet Oncol 2010, 11:55-65. 
11. Dowsett M, Cuzick J, Wale C, Forbes J, Mallon EA, Salter J, Quinn E, Dunbier A, Baum M, Buzdar A, Howell A, Bugarini R, Baehner FL, Shak S: Prediction of risk of distant recurrence using the 21-gene recurrence score in node-negative and node-positive postmenopausal patients with breast cancer treated with anastrozole or tamoxifen: a TransATAC study. J Clin Oncol 2010, 28:1829-1834.

12. Goldstein LJ, Gray R, Badve S, Childs BH, Yoshizawa C, Rowley S, Shak S, Baehner FL, Ravdin PM, Davidson NE, Sledge GW Jr, Perez EA, Shulman LN, Martino S, Sparano JA: Prognostic utility of the 21-gene assay in hormone receptor-positive operable breast cancer compared with classical clinicopathologic features. J Clin Oncol 2008, 26:4063-4071.

13. Mamounas EP, Tang G, Fisher B, Paik S, Shak S, Costantino JP, Watson D, Geyer CE Jr, Wickerham DL, Wolmark N: Association between the 21-gene recurrence score assay and risk of locoregional recurrence in nodenegative, estrogen receptor-positive breast cancer: results from NSABP B-14 and NSABP B-20. J Clin Oncol 2010, 28:1677-1683.

14. Paik S, Shak S, Tang G, Kim C, Baker J, Cronin M, Baehner FL, Walker MG Watson D, Park T, Hiller W, Fisher ER, Wickerham DL, Bryant J, Wolmark N: A multigene assay to predict recurrence of tamoxifen-treated, node-negative breast cancer. N Engl J Med 2004, 351:2817-2826.

15. Paik S, Tang G, Shak S, Kim C, Baker J, Kim W, Cronin M, Baehner FL, Watson D, Bryant J, Costantino JP, Geyer CE Jr, Wickerham DL, Wolmark N: Gene expression and benefit of chemotherapy in women with node-negative, estrogen receptor-positive breast cancer. J Clin Oncol 2006, 24:3726-3734.

16. Tang G, Shak S, Paik S, Anderson S, Costantino J, Geyer C Jr, Mamounas E, Wickerham D, Wolmark N: Comparison of the prognostic and predictive utilities of the 21-gene Recurrence Score assay and Adjuvant! for women with node-negative, ER-positive breast cancer: results from NSABP B-14 and NSABP B-20. Breast Cancer Res Treat 2011, 127:133-142.

17. Toi M, Iwata H, Yamanaka T, Masuda N, Ohno S, Nakamura S, Nakayama T, Kashiwaba M, Kamigaki S, Kuroi K: Clinical significance of the 21-gene signature (Oncotype DX) in hormone receptor-positive early stage primary breast cancer in the Japanese population. Cancer 2010, 116:3112-3118.

18. Yamauchi H, Nakagawa C, Takei H, Chao C, Yoshizawa C, Yagata H, Yoshida A, Hayashi N, Hell S, Nakamura S: Prospective study of the effect of the 21-gene assay on adjuvant clinical decision-making in Japanese women with Estrogen Receptor-Positive, Node-Negative, and Node-Positive Breast Cancer. Clin Breast Cancer 2013, 14:191-197.

19. Statistics Bureau of Japan: Portal site of the official statistics of Japan, 2010 Base consumer price index: indices of subgroups (1970 - the Recent Year). http://www.e-stat.go.jp/SG1/estat/ListE.do?bid=000001033700\&cycode=0.

20. Ministry of Health Labour and Welfare: Final report of monthly labour survey - March 2014 - TBL-T-1 wage indices. http://www.mhlw.go.jp/ english/database/db-l/26/2603re/2603re.html.

21. Ramsey S, Willke R, Briggs A, Brown R, Buxton M, Chawla A, Cook J, Glick H, Liljas B, Petitti D, Reed S: Good research practices for cost-effectiveness analysis alongside clinical trials: the ISPOR RCT-CEA Task Force report. Value Health 2005, 8:521-533.

22. Ishiguro H, Kondo M, Hoshi SL, Takada M, Nakamura S, Teramukai S, Yanagihara K, Toi M: Economic evaluation of intensive chemotherapy with prophylactic granulocyte colony-stimulating factor for patients with high-risk early breast cancer in Japan. Clin Ther 2010, 32:311-326.

23. Kondo M, Hoshi SL, Yamanaka T, Ishiguro H, Toi M: Economic evaluation of the 21-gene signature (Oncotype DX) in lymph node-negative/positive, hormone receptor-positive early-stage breast cancer based on Japanese validation study (JBCRG-TR03). Breast Cancer Res Treat 2011, 127:739-749.

24. Hillner BE, Smith TJ: Efficacy and cost effectiveness of adjuvant chemotherapy in women with node-negative breast cancer. a decisionanalysis model. N Engl J Med 1991, 324:160-168.

25. Ministry of Health Labour and Welfare: Abridged life table in 2011 (Female). http://www.e-stat.go.jp/SG1/estat/GL08020101.do?_toGL08020101_ \&tstatCode $=000001031336 \&$ requestSender $=$ dsearch.

26. Bonomi AE, Boudreau DM, Fishman PA, Ludman E, Mohelnitzky A, Cannon EA, Seger D: Quality of life valuations of mammography screening. Qual Life Res 2008, 17:801-814.

27. Hall J, Gerard K, Salkeld G, Richardson J: A cost utility analysis of mammography screening in Australia. Soc Sci Med 1992, 34:993-1004.

28. Lindley C, Vasa S, Sawyer WT, Winer EP: Quality of life and preferences for treatment following systemic adjuvant therapy for early-stage breast cancer. J Clin Oncol 1998, 16:1380-1387.
29. Hornberger J, Doberne J, Chien R: Laboratory-developed test-SynFRAME: an approach for assessing laboratory-developed tests synthesized from prior appraisal frameworks. Genet Test Mol Biomarkers 2012, 16:605-614.

30. Davidson JA, Cromwell I, Ellard SL, Lohrisch C, Gelmon KA, Shenkier T, Villa D, Lim H, Sun S, Taylor S, Taylor M, Czerkawski B, Hayes M, Ionescu DN, Yoshizawa C, Chao C, Peacock S, Chia SK: A prospective clinical utility and pharmacoeconomic study of the impact of the 21-gene Recurrence Score $(R)$ assay in oestrogen receptor positive node negative breast cancer. Eur J Cancer 2013, 49:2469-2475.

31. Tsoi DT, Inoue M, Kelly CM, Verma S, Pritchard Kl: Cost-effectiveness analysis of recurrence score-guided treatment using a 21-gene assay in early breast cancer. Oncologist 2010, 15:457-465.

32. Mount Hood 4 Modeling Group: Computer modeling of diabetes and its complications: a report on the Fourth Mount Hood Challenge Meeting. Diabetes Care 2007, 30:1638-1646.

33. Ruhnke GW, Wilson SR, Akamatsu T, Kinoue T, Takashima Y, Goldstein MK, Koenig BA, Hornberger JC, Raffin TA: Ethical decision making and patient autonomy: a comparison of physicians and patients in Japan and the United States. Chest 2000, 118:1172-1182.

doi:10.1186/1472-6963-14-372

Cite this article as: Yamauchi et al: Societal cost-effectiveness analysis of the 21-gene assay in estrogen-receptor-positive, lymph-node-negative early-stage breast cancer in Japan. BMC Health Services Research 2014 14:372.

\section{Submit your next manuscript to BioMed Central and take full advantage of:}

- Convenient online submission

- Thorough peer review

- No space constraints or color figure charges

- Immediate publication on acceptance

- Inclusion in PubMed, CAS, Scopus and Google Scholar

- Research which is freely available for redistribution

Submit your manuscript at www.biomedcentral.com/submit
C BioMed Central 